\title{
Results of 100 aphakic detachments treated with a temporary balloon buckle: a case against routine encircling operations*
}

\author{
HARVEY LINCOFF,' INGRID KREISSIG, ${ }^{2}$ AND MATTHEW FARBER' \\ From the 'Department of Ophthalmology of the New York Hospital-Cornell Medical Center, and the \\ ${ }^{2}$ Universitäts-Augenklinik, Tübingen, West Germany
}

SUMMARY One hundred patients with aphakic detachment were treated with temporary balloon buckles. The balloons were deflated and withdrawn after seven to 10 days. Permanent attachment depended on cryo- or laser-induced adhesions round the break. The procedure was initially successful in 79 patients. Ten retinas became detached again after the balloon was withdrawn and required a more permanent buckle. Sixty-nine retinas remained attached. The final results after additional operations were equivalent to those obtained by traditional methods, but significantly fewer complications occurred. The balloon procedure tests the validity of routinely encircling aphakic detachment.

Between June 1977 and February 1984 the authors treated 100 aphakic detachments with temporary balloon buckles in a prospective trial. The wisdom of including aphakic detachments in the balloon trial may be questioned. Aphakic detachment is thought to be associated with a special degree of vitreous traction and multiple undetectable holes in the retinal periphery.' For these reasons it has been almost universally treated with an encircling band. The band is supposed to counter.the special traction and to wall away the small undetected breaks.

\section{Materials and methods}

\section{PATIENTS}

Each of the 100 patients who were selected for the balloon procedure had suffered a retinal detachment thought to be caused either by a single break or by a group of closely placed breaks that did not subtend a retinal arc greater than $6 \mathrm{~mm}$, or 1 clock hour, as measured at the equator. The patients were consecutive and otherwise unselected. Forty-five patients were treated in Tübingen, West Germany, and 55 in

*The John Milton McLean medal lecture to the Cornell Alumni, New York, 4 May 1984.

Correspondence to H Lincoff, MD, Department of Ophthalmology, New York Hospital, 525 E 68th Strect, New York, New York 10021, USA.
New York. Ninety-four patients had undergone an intracapsular lens extraction and six an extracapsular procedure. Five of the 94 had received iris-supported intraocular lenses (Table 1). The time interval following the cataract operation was less than one week for 16 patients and more than one year for 57 (Table 2).

The detachments were confined to one or two quadrants in 63 patients and to three quadrants in 24 ; they were total in 13 (Table 3). The macula was attached in 45 patients, partly detached in nine, and completely detached in 46 (Table 4 ). The retina had been detached for less than one week in 43 patients and for more than one month in 11 (Table 5). Of the retinal breaks that could be identified 85 were flap tears, horseshoe in shape, and 10 were round. In five patients the shape of the break could not be determined; the balloon was used to probe an area of suspicion in the retina that was thought most likely to contain the superior break. ${ }^{2}$ In 47 cases the break was beneath or adjacent to a rectus muscle, and it was necessary to place the balloon at least partly beneath the muscle. The average distance of breaks from the limbus was $13 \mathrm{~mm}$ (Table 6).

Some evidence of preretinal traction was found in 64 patients. Unequivocal evidence was present in 24 , in the form of star folds in 11 eyes and vitreous incarcerated in the cataract wound in 13 eyes. In 40 


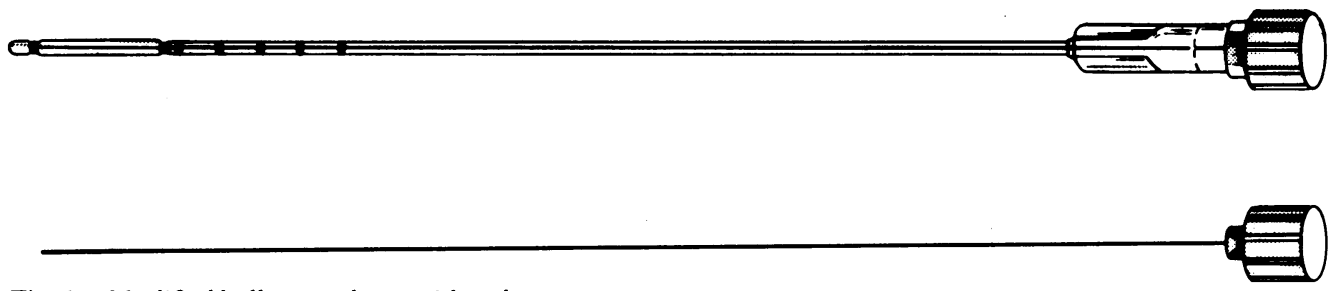

Fig. 1 Modified balloon catheter with stylette.

Table 1 Type of cataract operation

\begin{tabular}{ll}
\hline Intracapsular & Extracapsular \\
\hline $94^{*}$ & 6 \\
\hline
\end{tabular}

*Five patients received intraocular lenses.

Table 2 Time elapsed following the cataract operation

\begin{tabular}{lll}
\hline$<8$ Weeks & 8 Weeksto l year & $>1$ Year \\
\hline 16 & 27 & 57 \\
\hline
\end{tabular}

Table 3 Extent of detachment

\begin{tabular}{ll}
\hline Quadrants & No. of patients \\
\hline 1 & 32 \\
2 & 31 \\
3 & 24 \\
4 & 13 \\
\hline
\end{tabular}

Table 4 Preoperative state of the macula

\begin{tabular}{lll}
\hline Attached & Partlydetached & Detached \\
\hline 45 & 9 & 46 \\
\hline
\end{tabular}

Table 5 Duration of retinal detachment

\begin{tabular}{llll}
\hline$<$ I Week & I Week-I month & $>$ I Month & Unknown \\
\hline 43 & 26 & 11 & 20 \\
\hline
\end{tabular}

Table 6 Characteristics of the actual breaks

\begin{tabular}{lr}
\hline Characteristic & No. \\
\hline Shape: & \\
$\quad$ horseshoc & 85 \\
round & 10 \\
$\quad$ unknown & 5 \\
Relationship to the muscles: & 17 \\
$\quad$ bencath a horizontal rectus & 30 \\
$\quad$ beneath a vertical rectus & \\
Distance from the limbus (mm): & 8 \\
most anterior & 22 \\
most postcrior & 13 \\
$\quad$ average & \\
\hline
\end{tabular}

Table 7 Possible vitreous traction

\begin{tabular}{ll}
\hline Evidence & No. \\
\hline Star folds & 11 \\
Vitreous incarceration & 13 \\
Circumferential linc & 40 \\
\hline
\end{tabular}

patients the presence of a prominent circumferential line in the retinal periphery that is presumed to harbour occult tears or to be vulnerable to subsequent tearing was noted (Table 7).

\section{MODIFIED BALLOON CATHETER}

Part way through the study (in April 1982) the balloon catheter was modified by shortening it to $15 \mathrm{~cm}$ and inserting a wire stylette that extended to the tip of the balloon. The stylette stiffens the catheter and balloon and enables it to be directed more precisely in Tenon's space (Fig. 1).

\section{TECHNIQUE}

The technique for aphakic patients was similar to one that had previously been described. ${ }^{3}$ Essentially, the break was localised transconjunctivally with the cryoprobe or the Urrets-Zavalia localiser and its location marked on the conjunctiva with ink. The balloon catheter with its stylette in place (in the latter part of the study) was inserted into the parabulbar space through a small puncture in the conjunctiva, was manoeuvered beneath the localising mark, and was inflated with $1 \mathrm{ml}$ of saline. Acting like a large elastic explant, it closed the retinal break and caused absorption of subretinal fluid in most patients. If a larger buckle was required, additional fluid was injected after an interval long enough for the intraocular pressure to return to normal (15 to 60 minutes) or on subsequent days.

The balloons in this series were deflated and withdrawn after an average of seven days (New York) or of $\mathbf{1 0}$ days (Tübingen). Permanent attachment was sought by one of two methods. In Tübingen adhesions were induced by contiguous transconjunctival cryopexy around the break prior to insertion of the balloon. In New York two rows of interrupted laser applications were used to encircle the break after it came in contact with the balloon buckle, usually on the day after insertion. 
All the patients underwent surgery under local anaesthesia. In New York 53 patients received a retrobulbar injection of $2 \mathrm{ml}$ of lignocaine $2 \%$, in two patients the balloon was inserted under topical amethocaine $1 \%$. In Tübingen, from 1983, the retrobular injection of lignocaine was replaced by a subconjunctival injection limited to the quadrant of the balloon insertion.

After surgery the patients were fully mobilised. They were examined daily for one week or until the balloon was withdrawn. One week after its withdrawal they were examined again, and if the retina was attached, they were allowed to resume their usual activities. They were asked to return for followup examinations at one month, six months, one year, and then yearly. They were taught how to check their visual fields and were advised to return immediately if they perceived a defect. The minimum follow-up for the patients in the series was six months, the maximum was 66 months, and the average was 32 months.

\section{Results}

ANATOMICAL RESULTS

In 88 patients the balloon closed the retinal break for which it was intended. Subretinal fluid was absorbed completely in 79 (after one day in 70) (Table 8). In the other nine patients reattachment was only partial. Although the balloon closed the break for which it was intended, fluid receded to the level of a second break that had not been detected prior to the operation (Fig. 2). The shape of the residual detachment pointed to the location of the second break, and it was found in seven patients. In five of the seven the second break was buckled with a sponge, and the remaining fluid was absorbed promptly. The other two patients recovered 20/200 vision when the superior parts of their retinas became reattached after the balloon insertion, and they refused a second

Table 8 Initial anatomical results of 100 balloon insertions

\begin{tabular}{lr}
\hline Reattachment & No. \\
\hline Complete & 79 \\
Partial & 9 \\
None & 12 \\
\hline
\end{tabular}

Table 9 Redetachment after deflation of balloon

\begin{tabular}{llll}
\hline Reason & No. & $\begin{array}{l}\text { Secondary } \\
\text { repair }\end{array}$ & $\begin{array}{l}\text { No. } \\
\text { Reattached }\end{array}$ \\
\hline Another break adjacent & 3 & Sponge & 3 \\
Traction & 7 & $\left\{\begin{array}{l}\text { sponge } \\
\text { encircling band } \\
\text { vitrectomy }\end{array}\right.$ & 3 \\
& & 2 \\
\hline
\end{tabular}

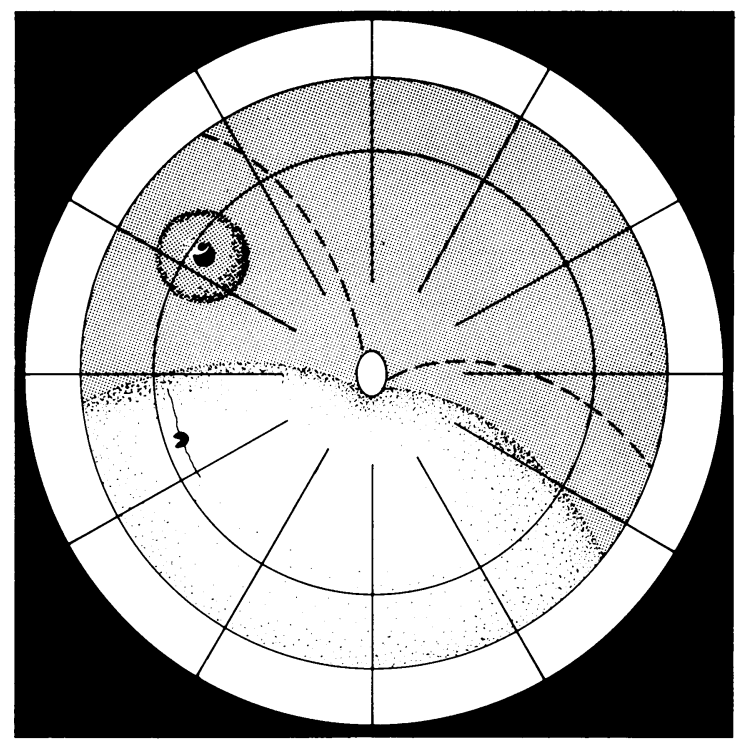

Fig. 2.Partial reattachment after balloon insertion beneath a retinal break at 10.15 o'clock. The shape of the residual detachment points to a second break at 8.15 o'clock. Broken line indicates upper border of original detachment.

operation. One of the two patients with a residual inferior detachment in which the break could not be found underwent three subsequent operations; preretinal proliferation developed, and the retina became totally detached. In the other patient a shallow inferior detachment has remained for two years. Speculative surgery has been deferred because he is uniocular, has 20/25 vision, and functions as an accountant.

Ten of the 79 patients whose retinas became completely attached after the balloon insertion experienced redetachment after the balloon was deflated and withdrawn (Table 9). In three patients a second undetected break adjacent to the primary break was the cause; it had been temporarily closed on the edge of the balloon buckle but reopened after the balloon was withdrawn (Fig. 3). In seven patients vitreous traction on the flap of the tear overcame the laser-induced adhesion and reopened the break (Fig. 4). All the redetachments occurred among the

Table 10 Failure to reattach with the balloon procedure

\begin{tabular}{lll}
\hline Reason & No. & $\begin{array}{l}\text { No. reattached } \\
\text { with reop. }\end{array}$ \\
\hline $\begin{array}{l}\text { Poor placement } \\
\text { of balloon }\end{array}$ & 3 & 3 \\
$\begin{array}{l}\text { Another break above } \\
\text { Traction }\end{array}$ & 5 & 1 \\
Break too posterior & 3 & 1 \\
\hline
\end{tabular}




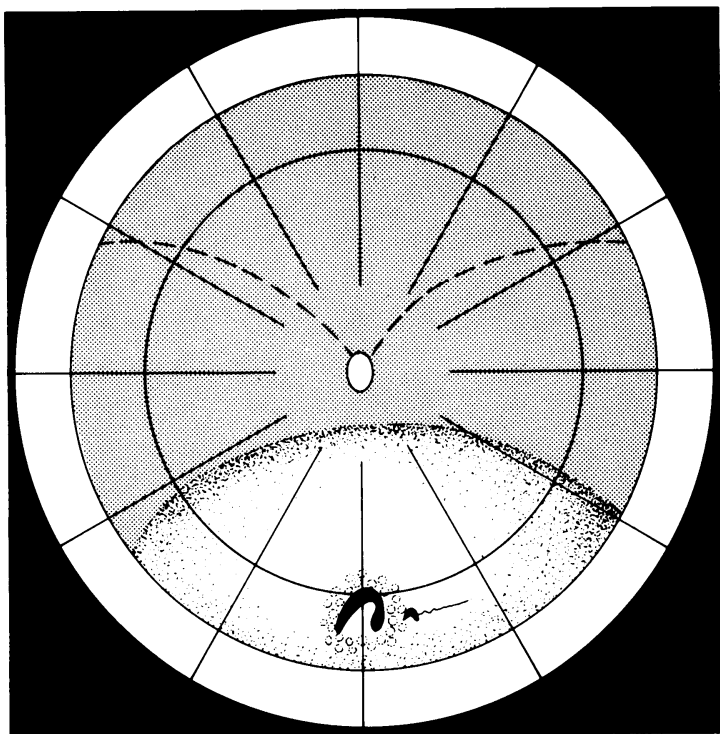

Fig. 3 Recurrent detachment after balloon deflation caused by an undetected break that had been supported on the edge of the balloon buckle. Broken line indicates original extent of detachment.

patients treated in New York, where the breaks were sealed with laser applications. All were repaired with local sponge explants and cryopexy; for two of them encircling bands were also used. Two patients eventually required a vitrectomy to sustain reattachment. None of the 79 patients whose retinas initially were reattached as the result of the balloon procedure failed to have final reattachment of the retina.

Twelve patients did not respond at all to insertion of the balloon (Table 10). In three the balloon was placed too far from the centre of the break, and an unsupported edge of the break leaked. All three retinas became reattached when the balloon was inserted in the correct place. In eight patients the procedure failed either because we never found the superior break (five patients) or because of unrelieved traction (three patients). The eight were treated with extensive circumferential buckles or encirclements, but only one retina in each category became reattached. In one patient - a diabetic with an iatrogenic break $22 \mathrm{~mm}$ from the limbus-the procedure failed when the balloon slipped into the

Table 11 Final anatomical results

\begin{tabular}{lc}
\hline Reattachment & No. \\
\hline Complete & 89 \\
Partial & 3 \\
None & 8 \\
\hline
\end{tabular}

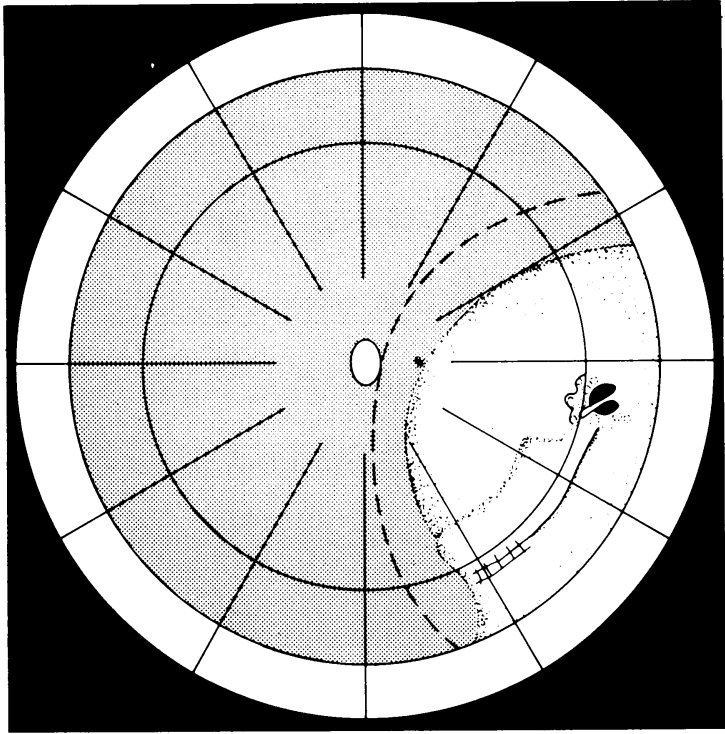

Fig. 4 Recurrent detachment after balloon deflation caused by excessive traction on the flap of the break. Broken line indicates original extent of detachment.

retrobular space and did not cause any buckling effect. It was subsequently learned that the balloon is not suitable for breaks in the posterior pole.

The final anatomical result after all the procedures was $89 \%$ attached (Table 11). This compares favourably with the results obtained by Norton. ${ }^{+}$Our patients were selected on the basis that they were presumed to have only one break and so had a better prognosis.

\section{VISUAL RESULTS}

The visual results are displayed in scattergrams that are categorised by whether the maculas prior to surgery were attached (Figs. 5a, b), were partly detached (Figs. 6a, b), or were completely detached (Figs. 7a, b).

At three to four weeks after surgery vision in most patients with preoperative macular attachment was unchanged or slightly improved, and the results clustered around 20/20 (Fig. 5a). Improvement was probably the result of clearing of the media. Four patients lost one or two lines temporarily. Although we did not confirm it with fluorescein, the cause was probably cystoid macular oedema. At six months those four had recovered, but four others had some loss-one from uncontrolled glaucoma, two from progressive macular degeneration, and one for undefined reasons (Fig. 5b).

In all but one of the patients with partial macular detachment prior to surgery visual acuity was main- 


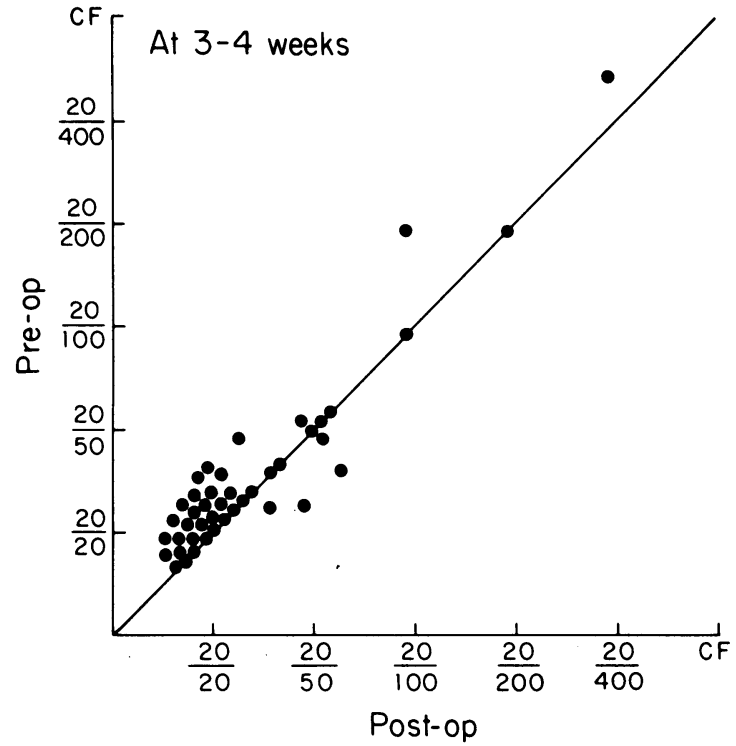

Fig. 5a

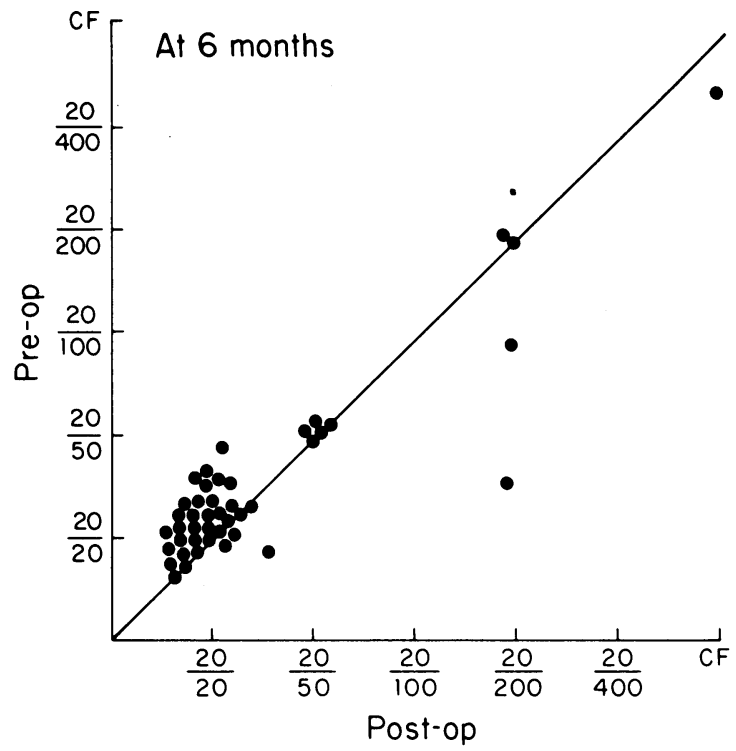

Fig. $5 b$

Fig. 5 Visual results in patients whose maculas were attached prior to balloon insertion. Patients whose visual acuity improved are represented by dots above the diagonal line, and those whose acuity diminished by dots below the line. (a). Results three to four weeks after surgery. (b) Results six months after surgery.

tained or improved at three to four weeks (Fig. 6a), and at six months $100 \%$ recovery was noted (Fig. 6b).

Approximately half the patients with preoperative macular detachment had improved visual acuity by

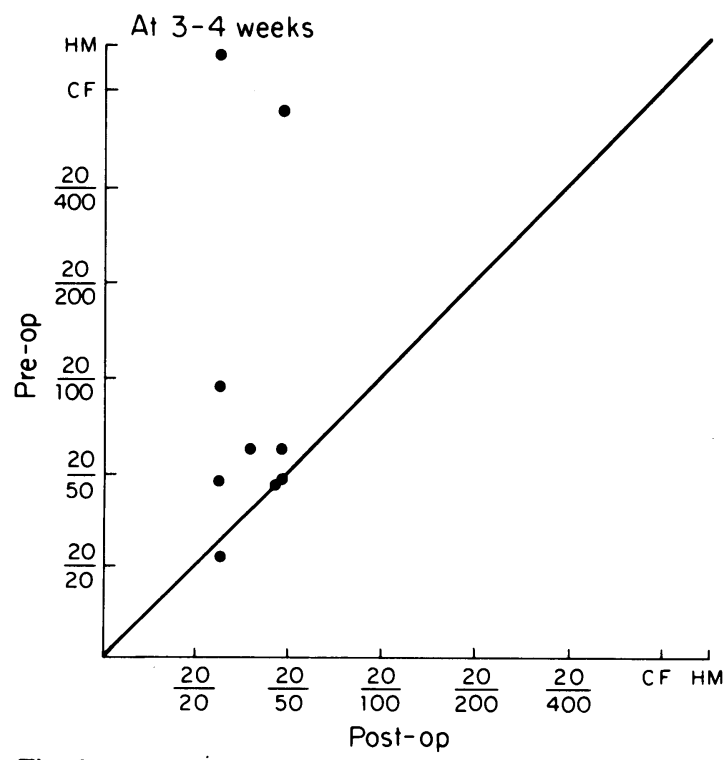

Fig. 6a

Fig. 6 Visual results in patients with partial macular detachment prior to surgery: (a) at three to four weeks after balloon insertion; (b) at six months postoperatively. 


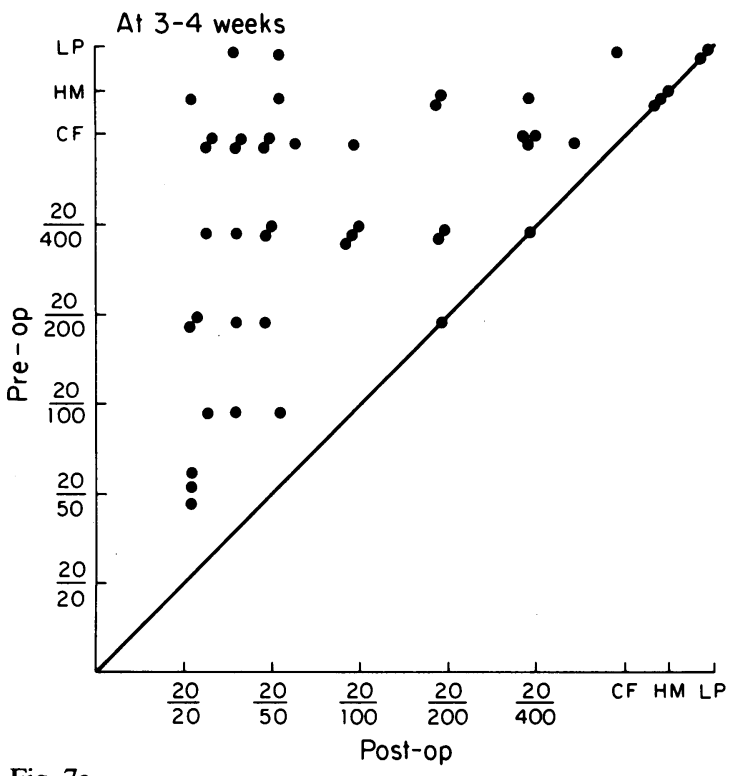

Fig. 7a

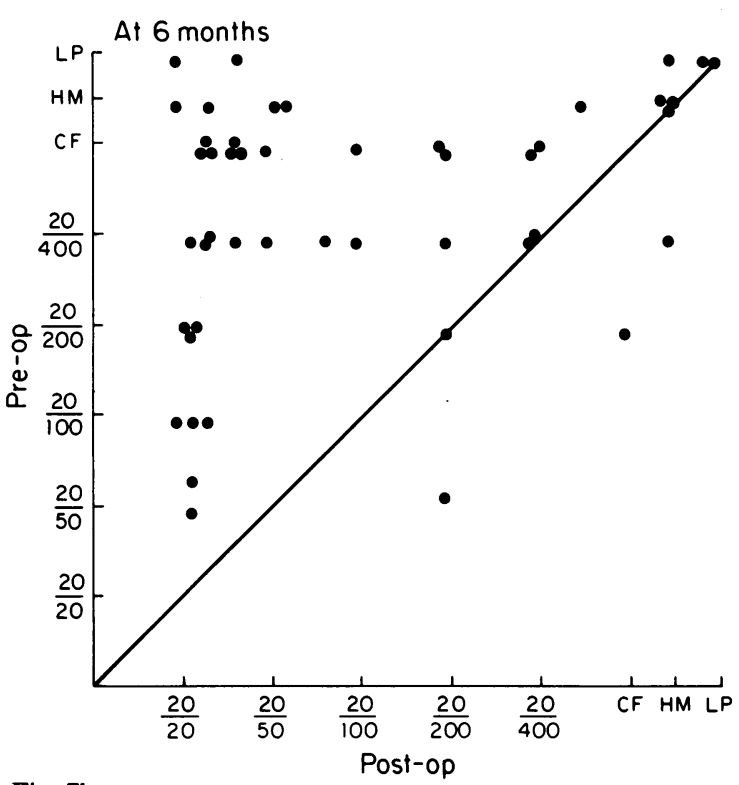

Fig. $7 b$

Fig. 7 Visual results in patients with macular detachment prior to balloon insertion: (b) at three to four weeks after surgery; (b) at six months postoperatively.

\section{COMPLICATIONS}

Superficial corneal erosion occurred in two patients because the catheter was improperly directed and abraded the epithelium. The corneas healed in one day when the catheter was redirected. Uveitis occurred twice. In one patient-the diabetic with the iatrogenic break near the posterior pole (see above) -it was severe. The balloon, which had slipped into the retrobulbar space, caused some venous obstruction and had to be removed on the second postoperative day. In the second patient the uveitis was mild and responded to local steroids. A macular pucker occurred in one patient who subsequently underwent multiple operations, including a vitrectomy for progressive proliferative vitreoretinopathy. Small choroidal effusions occurred in two patients and resolved spontaneously. There were no infections. It is worth noting that, although the balloon intruded beneath a rectus muscle in 47 cases and beneath a vertical in 30 , the muscles nevertheless functioned normally within hours after the balloon was deflated and removed, and diplopia did not occur (Table 12).

Table 12 Complications of the balloon insertion

\begin{tabular}{ll}
\hline Type & No. \\
\hline Superficial corneal crosion & 2 \\
Uveitis & 2 \\
Macular pucker & 1 \\
Choroidal effusion & 2 \\
Diplopia (47) & 0 \\
\hline
\end{tabular}

\section{Discussion}

The 100 patients in this trial were presumed to have one break each of less than $6 \mathrm{~mm}$ and therefore constituted a group with a favourable prognosis. Nevertheless, many of them would have been treated with an encircling buckle because they were aphakic, and thus it was presumed that special tractional components as well as undetectable breaks in the retinal periphery were present. Norton ${ }^{4}$ in his classic paper refuted the importance of special traction in aphakic detachment, but he supported the presumption of undetectable breaks in the periphery.

In our series special traction, defined here as traction sufficient to separate an unsupported laser or cryoinduced adhesion after the balloon was deflated, occurred in seven cases. That is three more than in a parallel series of phakic detachments treated with the balloon. ${ }^{5}$ This difference is not significant by a onetrailed test with a $95 \%$ confidence interval. ${ }^{\circ}$

A better case can be made for the presumption that aphakic detachments tend to be associated with small breaks that are difficult to find. In three patients such a break occurred close to the primary break and was discovered only after the balloon was deflated and redetachment occurred. A second break below and more remote from the primary break was present in nine patients.

An encircling band or even a short sponge would have captured the adjacent breaks, but whether an 
encircling band as a first procedure would have closed the remote undetected breaks is questionable. In five patients in whom a break could not be found encircling buckles placed speculatively beneath the presumptive traction line in the periphery if it was present, or if not at $13 \mathrm{~mm}$, succeeded in closing an undetected break only once. These results differ from Norton's experience, in which a speculative encirclement in 23 patients with undetected breaks succeeded in reattaching the retina in 20 . Those figures, expressed as $87 \%$, have had a profound effect on the management of aphakic detachment. We cannot reconcile them with our experience.

Could encirclement serve a prophylactic purpose in preventing subsequent breaks? Our series does not justify the procedure. Only one patient developed an additional break within six months after the initial reattachment.

We suggest that the routine use of encircling bands in aphakic detachment came about because, when the indirect ophthalmoscope brought the aphakic ora readily into view, magnification of the 20 dioptre lens was insufficient to show the difference between cysts and holes or tags and tears in the periphery. With the advent of the biomicroscopic technique that uses a three-mirror-contact lens in conjunction with scleral depression to study the periphery small breaks in the retinal periphery can be identified with more certainty. In this series $95 \%$ of superior breaks were found, and all but two of the inferior breaks after their presence was indicated by residual detachment. The need to wall away stretches of peripheral retina because they might harbour additional breaks has diminished.

Why not encircle anyway? First, encirclement is a four-quadrant procedure with significant complications. ${ }^{47}$ If used in combination with extensive coagulation it handicaps further efforts to reattach the retina should the encirclement fail. Secondly, it promotes radial folds and so is less effective than the local use of buckles in closing retinal breaks. ${ }^{k}$ Lastly, Yoshida et al. ${ }^{9}$ have recently shown that constriction of the eye with an encircling band, even when it is limited to the 10 to $20 \%$ that we once recommended as a safe limit, ${ }^{7}$ causes chronic ischaemia. Dobbie ${ }^{11}$ demonstrated that encirclement diminishes the amplitude of the ocular pulse. Winter and Lipka" reported diminished retinal sensitivity in patients who underwent an encircling procedure.

This report recommends the use of the balloon as an initial procedure in managing selected (one break) aphakic detachments. In the series reported here the reattachment rate after one procedure was $10 \%$ less than might have been expected from local implantation of a sponge. Nevertheless, for 69 of the 100 patients the initial insertion of the balloon in conjunction with cryo or laser surgery caused permanent reattachment of the retina. For the remainder the use of the balloon defined the reasons for the retina's failure to become reattached and left a relatively uninjured eye on which to operate again.

We acknowledge with appreciation the editorial assistance of Suzanne Javitt and MaricElena Caulfield.

This work was supported by grants from Prince Abdullah Faisal and Mr Edward Grayson.

\section{References}

1 Benson WE. Retinal detachment. Hagerstown: Harper and Row, 1980: 30-1.

2 Lincoff $\mathrm{H}$, Kreissig I. Diagnostic uses for an unsecured balloon buckle. Mod Probl Ophthalmol 1979; 20: 157-63.

3 Lincoff $\mathrm{H}$, Kreissig I, Hahn YS. A temporary balloon buckle for the treatment of small retinal detachments. Ophthalmology (Rochester) 1979; 86: 586-92.

4 Norton EWD. Retinal detachment in aphakia. Trans Am Ophthalmol Soc 1963; 61: 770-89.

5 Lincoff $\mathrm{H}$, Kreissig I. Results with a temporary balloon buckle for the repair of retinal detachment. Am J Ophthalmol 1981; 92: 245-51.

6 Sanders DH, Murph AF, Eng RJ. Statistics: a fresh approach. New York: McGraw-Hill, 1980.

7 Lincoff H, Kreissig I, Parver L. Limits of constriction in the treatment of retinal detachment. Arch Ophthalmol 1976; 94: 1473-7.

8 Lincoff $\mathrm{H}$. The rationalc for radial buickling. Mod Probl Ophthalmol 1974; 12: 484-91.

9. Yoshida A, Feke G, Green GJ, et al. Retinal circulatory changes after scleral buckling procedures. Am J Ophthalmol 1983; 95: 182-91.

10 Dobbic G. Circulatory changes in the cye associated with retinal detachment and its repair. Trans Am Ophthalmol Soc 1980); 78: 504-66.

11 Winter W, Lipka P. Differenzierte Wertung des funktionellen Ergebnisses nach Ablatio-Operation. Ber. XIV. Kongress Ges. Augenärzte der DDR. 1984. 